\title{
Ketoacidosis during diabetes mellitus: epidemiological, clinical and management aspects in Malabo - Equatorial Guinea
}

Amadou Kaké ${ }^{*}$, Djibril Sylla² ${ }^{2}$ Mohamed Yakharé Camara² ${ }^{2}$ Thierno Amadou Wann², Ibrahima Camara ${ }^{1}$, Toumin Camara² ${ }^{2}$ Mohamed M'mah Diaby ${ }^{3}$, Maciri Samaké ${ }^{3}$, Nguema Elvira Andeme ${ }^{3}$ and Alioune Camara ${ }^{4}$

*Correspondence: amadoukake@gmail.com

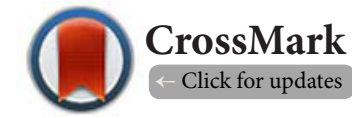

'Department of Endocrinology and Diabetology, Teaching Hospital of Conakry- Guinea.

${ }^{2}$ Department of Internal Medicine, Teaching Hospital of Conakry - Guinea.

${ }^{3}$ Department of Public Health, University Gamal Abdel Nasser of Conakry - Guinea.

${ }^{4}$ Department of Internal Medicine, Polyclinic Dr Loeri Comba (PLC) of Malabo - Equatorial Guinea.

\begin{abstract}
Introduction: Ketoacidosis is the most common hyperglycemic emergency in diabetic patients. Sometimes ketoacidosis can be observed during a decompensation process in diabetic conditions. Its prognosis is related to the identification and treatment of underlying decompensation factors. The objectives of this study were to report on the frequency of ketoacidosis to the Department of Internal Medicine, to identify the decompensation factors observed and highlight the challenges associated with its management.

Patients and Method: We prospectively examined a consecutive series of diabetic patients hospitalized at the PLC from January to July 2013 with a diagnosis of diabetic ketoacidosis. Ketoacidosis was defined as the combination of fasting blood glucose $\geq 250 \mathrm{mg} / \mathrm{dl}$, glycosuria and ketonuria equal to or greater than two crosses in a semi-quantitative estimate. The study parameters were: the age, the sex, the type and the known duration of evolution of the diabetes, the factors leading to decompensation and challenges related to its management.

Results: During the study period, 23 cases of ketoacidosis were observed out of 350 hospitalized patients,a prevalence of $6 \%$. The sex ratio was 1.87 . The average age of patients was $35 \pm 10$ years with extremes of 16 years and 53 years. Type 2 diabetes was the most common with a prevalence of $77 \%$. Half of the cases $(50 \%)$ were unknown. All patients had a recorded blood glucose level of above $400 \mathrm{mg} / \mathrm{dl}$ with at least 2-cross of ketonuria. Eighty-seven percent of the patients have no knowledge of the condition. Three deaths were recorded (13\%) among uninsured patients.

The following decompensation factors were observed: rupture of treatment in 7 cases (32\%), infection in 17 cases (77\%), dietary error in 15 cases (68\%), and inadequate treatment in 3 cases (14\%), difficulties of insulin therapy in 5 cases $(22 \%)$. These factors were associated in 10 cases $(46 \%)$.

Conclusion: Ketoacidosis is common among diabetic patients hospitalized in Malabo. The decompensation factors identified among others are lack of knowledge among target patients.
\end{abstract}

Keywords: Ketoacidosis, diabetes, decompensation, Equatorial Guinea

\section{Introduction}

Diabetic ketoacidosis (DKA) is the most common and most serious of diabetological emergencies [1]. In Africa, it is often inaugural, but can be observed during the decompensation of already known diabetes. Its prognosis remains formidable with a mortality rate of 5 to $21 \%[1,2]$. It depends on the identification and treatment of underlying decompensation factors. In resource-limited settings, education of diabetic patients is an important to reducing the frequency and severity of this acute complication of diabetes. There is no data published on 
Kaké et al. Internal Medicine Inside 2018,

the DKA in Equatorial Guinea. The objectives of this study were to report on the frequency of DKA to the Department of Internal Medicine to Dr. Loeri Comba Polyclinic (PLC) of Malabo, to identify the decompensation factors observed and, to identify the difficulties associated with its management.

\section{Patients and method}

This is a descriptive and cross-sectional analytical study with a prospective of collecting data from January to October 2013. It was conducted at the Internal Medicine Department of the Polyclinic of Dr. Loeri Comba (PLC) of Malabo (Equatorial Guinea). Patients of 16 years and older diagnosed with diabetic ketoacidosis was included in this study. There was no exclusion, the only exclusions was the refusals to participate in the study. This study utilized data collected from consultation registers, hospital records, patients' notebooks. Survey cards were also prepared for use in this study.

We systematically examined a consecutive series of diabetic patients hospitalized at the PLC during the study period who were diagnosed with diabetic ketoacidosis. All of these patients underwent careful clinical examination, followed by the search for associated glycosuria and ketonuria in freshly expelled urine.

Ketoacidosis has been defined by the association of dyspnea as acidosis or dyspnea ofKussmaul at a fasting glucose level $\geq 250 \mathrm{mg}$ / dl, glycosuria and ketonuria greater than or equal to two crosses, in a semi-quantitative estimate. We did not have the opportunity to perform a gasometry or a dosage of bicarbonates.

The following Variables have been determined:

- Person characteristics of patients: age and sex.

- The variables describing diabetes: blood glucose at admission, type of diabetes and known duration of diabetes. Diabetes typing was based on a combination of clinical and evolutionary arguments (age of patient, morphotype, time to onset of symptoms, family history, and course of treatment). Anti-GAD and anti-IA2 antibodies have not been achieved.

- The factors of decompensation of the sought diabetes were: rupture of treatment, infection (in particular cutaneous, otorhinolaryngological, dental, pulmonary and urinary), dietary error (jump of meals, nibbling), error in the administration of the insulin (injection technique, rotation of sites, dose adjustment), poor quality of drugs in terms of expiry and preservation.

The data collected were entered and analyzed in Epi info software version6.

\section{Results}

A total of 350 patients including 115 diabetic patients were hospitalized during the study period, Of these, 23 cases of diabetic ketoacidosis were identified. The total prevalence was $6 \%$ ( $20 \%$ among diabetic patients).

There were 15 men against 8 women with a sex ratio of 1.87 in favor of men. The average age of patients was $35 \pm 10$ years with extremes of 16 years and 53 years.

Type 2 diabetes was the most common $77 \%$. Half of the cases (50\%) were unknown. All patients had a blood glucose level above $400 \mathrm{mg} / \mathrm{dl}$ with at least one 2-cross ketonuria. Fortyseven percent of the patients had received no education and $70 \%$ had no diabetes surveillance systems. Half of the patients never benefited from an insurance cover. Three cases of death were recorded (13\%), all of whom were uninsured patients.

Table 1 summarizes the main decompensation factors found in patients with ketoacidosis. A break in treatment was noted in 7 cases (32\%). At least one infection was present among 17 patients (77\%), including one in 6 cases (35\%), one urogenital infection in 5 cases (29\%) and one in 4 cases (24\%). A dietary error was found in 15 cases (68\%): taking a single meal a day, meal schedules orsnacking not respected. An inappropriate treatment in 3 cases (14\%) including oral antidiabetic drugs for type 1 diabetes and poor quality drugs were used by 2 patients (expiry date exceeded in one case and insulin denatured by lack of storage at an adequate temperature in a case). Difficulties of insulin therapy were noted in 5 cases (22\%): errors in the injection technique with non-rotation of injection routes and errors in the adjustment of insulin doses.

Table 1. Decompensation factors for ketoacidosis ( $n=23$ patients).

\begin{tabular}{ll}
\hline Decompensation Factors & Cases number (\%) \\
\hline A break in treatment & $7(32)$ \\
Infection & $17(77)$ \\
A dietary error & $15(68)$ \\
Inappropriate treatment & $3(14)$ \\
Difficulties of insulin therapy & $5(22)$ \\
Non determined & $2(8.6)$ \\
\hline
\end{tabular}

In 10 cases (46\%), several decompensation factors were present in the same patient.

Among the causes of treatment failure $(n=7)$, three patients mentioned financial reasons leading them to reduce their doses of medication (oral antidiabetic or insulin) or even to the break of treatment, Unavailability of the drug prescribed by default of supply was mentioned by 2 patients and 2 patients had stopped their treatment and resulted traditional treatment means. The main difficulties noted were: delay in seeking healthcare, the unavailability of certain drugs, the inaccessibility of drugs and check-ups (especially for the uninsured) and the lack of training of staff in the management of diabetological emergencies.

\section{Discussion}

The hospital prevalence of diabetic ketoacidosis in our series was $6 \%$ ( $20 \%$ when reported to diabetic patients only). A comparable prevalence has been found in other African series; $6.49 \%$ by Leye in Senegal [2] 4.4\% by Lokrou [3] in Côte d'Ivoire and $6.87 \%$ by Simaga in Mali [4] and Ouédraogo in 
Kaké et al. Internal Medicine Inside 2018,

Burkina Faso, had found a prevalence of 8.24\% [5]. However, a higher prevalence was found in other series $35 \%$ by Baldé in Guinea [1], 35.9\% by Dionadji M in Ndjamena [6].

The average age of onset of DKA in our series was $35 \pm 10$ years with extremes of 16 years and 53 years. This average age is relatively young compared to most African series, which places this average age around 50 [1-3]. This could be explained on the one hand, by the fact that in our series it was about a discovery of diabetes in half of the cases and on the other hand by the notion of diabetes of the African type or atypical diabetes mellitus at ketotic tendency [7].

We found a clear male predominance, 15 men versus 8 women with a sex ratio of 1.87 in favor of men. A female predominance has been found in other African series $[\mathbf{2}, \mathbf{8}, \mathbf{9}]$.

Type 2 diabetes accounted for $77 \%$ of patients in our series. In Africa, the frequency of decompensation observed during type 2 diabetes is significant. This may be related to the frequency of a particular diabetes (type b2) by its tendency to ketosis and the reversibility of its treatment with insulin $[7,10]$.

Diabetic ketoacidosis was the circumstance of discovery of diabetic disease in half of our patients (50\%); this frequency is substantially comparable to the results found in the series of Pouye and al. [11], with an inaugural DKA in $41.17 \%$ of cases. It was also the mode of revelation of diabetes in adults in other African series, including that of Lokrou and al. [3] in Côte d'Ivoire, and that of Leye MY and al. [2] in Senegal; with respective prevalence of $36.6 \%$ and $38.24 \%$.

The insignificant proportion of type 2 diabetics for whom DKA was inaugural could be explained by the existence in black subjects of a form of atypical diabetes occurring in middle-aged patients whose discovery would be inaugurated

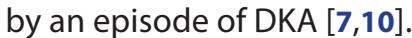

Infection and dietary errors were the main decompensation factors in our practice with $77 \%$ and $68 \%$ respectively.
This prevalence of infection was also found by other authors [1-3,5,8,9,11-13].

Acute complications of diabetes mellitus occur mainly in patients with very little information about their disease and especially its complications. In our series, only $13 \%$ of patients had a formal education about their disease. Among known diabetic patients, $32 \%$ did not follow their treatment, $14 \%$ had inappropriate treatment and $22 \%$ of those who were treated with insulin had difficulty administering it. This finding could be explained by the lack of knowledge of diabetes, the lack of qualified personnel, the unavailability of drugs, especially insulin, and the difficulties in meeting prescriptions over a long period.

In $8.6 \%$ of cases, no decompensation factor was identified in our series. The same observation was noted in other African publications [1,14]. In fact, the decompensation factors are not always identified, given the systematic failure to perform blood culture and cytobacteriological examinations of the urine (CBEU) and the abusive use (self-medication) of antibiotics.

The death rate (13\%) noted in our series and the associated factors are comparable to those noted in the African literature [15]. These include infection, delayed diagnosis and management, the great indigence of patients and lack of training of staff in the management of diabetological emergencies.

\section{Conclusion}

Diabetic ketoacidosis is common in Malabo. It is the inaugural type 2 diabetes in the majority of cases. The decompensation factors identified are accessible to targeted patient education. In addition to staff training, funding and accessibility to care, including drugs, needs to be improved.

\section{Competing interests}

The authors declare that they have no competing interests.

Authors' contributions

\begin{tabular}{|l|c|c|c|c|c|c|c|c|c|c|}
\hline Authors' contributions & KA & SD & CMY & WT & CT & CA & DMM & SM & CI & ANE \\
\hline Research concept and design & $\checkmark$ & $\checkmark$ & $\checkmark$ & $\checkmark$ & $\checkmark$ & $\checkmark$ & $\checkmark$ & -- & $\checkmark$ & -- \\
\hline Collection and/or assembly of data & $\checkmark$ & $\checkmark$ & $\checkmark$ & $\checkmark$ & $\checkmark$ & $\checkmark$ & $\checkmark$ & $\checkmark$ & -- & $\checkmark$ \\
\hline Data analysis and interpretation & $\checkmark$ & $\checkmark$ & $\checkmark$ & $\checkmark$ & $\checkmark$ & $\checkmark$ & $\checkmark$ & $\checkmark$ & $\checkmark$ & $\checkmark$ \\
\hline Writing the article & $\checkmark$ & $\checkmark$ & $\checkmark$ & $\checkmark$ & $\checkmark$ & $\checkmark$ & $\checkmark$ & $\checkmark$ & $\checkmark$ & $\checkmark$ \\
\hline Critical revision of the article & $\checkmark$ & $\checkmark$ & $\checkmark$ & $\checkmark$ & $\checkmark$ & $\checkmark$ & $\checkmark$ & $\checkmark$ & $\checkmark$ & $\checkmark$ \\
\hline Final approval of article & $\checkmark$ & $\checkmark$ & $\checkmark$ & $\checkmark$ & $\checkmark$ & $\checkmark$ & $\checkmark$ & $\checkmark$ & $\checkmark$ & $\checkmark$ \\
\hline Statistical analysis & $\checkmark$ & $\checkmark$ & $\checkmark$ & $\checkmark$ & -- & $\checkmark$ & -- & -- & $\checkmark$ & -- \\
\hline
\end{tabular}

Acknowledgement

Our thanks to Mr Omar MBakeh for the translation and to the entire team of the Internal Medicine Department of Dr. Loeri Comba Polyclinic

Publication history

EIC: Fabio Angeli, University of Perugia, Italy.

Received: 10-Sept-2018 Final Revised: 08-Nov-2018

Accepted: 12-Nov-2018 Published: 28-Nov-2018 
Kaké et al. Internal Medicine Inside 2018,

\section{References}

1. Baldé NM, Barry AY, Diallo MM, Kaké A BD, Camara A and Diallo MSK $S M B$. Cétoacidose au cours du diabète sucré à Conakry : fréquence et facteurs de risque de décompensation, nécessité d'une éducation ciblée. Ann l'Université Ouagadougou - série D. 2006; 004:52-67.

2. Leye MY, Leye A, Ndiaye N, Ngo VB, Touré PS and Ndour MA. Aspects épidémiologiques et diagnostiques de la cétoacidose diabétique en milieu hospitalier à Dakar. Analyse de $\mathbf{1 0 2}$ cas au CHU de Pikine. Rev Africaine Médecine Interne. 2016; 3:8-11. | Article

3. Lokrou A Z-GC. L'acidocétose diabétique en côte d'Ivoire : Etude d'une population féminine homogène au CHU de Treichville. Proposition d' une stratégie adaptée pour l'Afrique . Rev Fr Endocrinol Clin. 1995; 36: 565-70.

4. Mme Simaga Mariam T. Diarra. Diabetes in the Resuscitation Department of the Gabriel Touré Hospital: Epidemiological and Clinical Aspects from January 2007 to December 2007 . Thèse Dr d'Etat. 2008; 1-89.

5. Ouedraogo M, Ouedraogo SM, Birba E and Drabo YJ. Complications aiguës du diabète sucré au Centre Hospitalier National Yalgado Ouedraogo. 2000; 47.

6. Dionadji M, Oumar A, Nodjito M and Ibrahim A. Prévalence des complications médicales chez les Diabétiques Hospitalisés à l'Hôpital Général de Référence Nationale de Ndjamena. Heal Sci Dis. 2015; 16:14. | Article

7. Belhadi L, Chadli A, Bennis L, Ghomari H, Farouqi A. Diabète atypique avec tendance à la cétose ou diabète " africain : à propos de deux cas Ketosis-prone atypical diabetes mellitus : report of two cases. 2018; 68: 470-4.

8. Sarr A, Diedhiou D, Ndour-Mbaye NM, Leye YM, Ka-Cisse MS, Leye A and Diop SN. [Ketoacidosis in type 1 diabetes mellitus: 73 cases in Dakar]. Mali Med. 2011; 26:50-4. | PubMed

9. Tchaou BA, Gomina $M$, Homère $A$, Agbo $M$ and Akpona SA. Complications aiguës métaboliques du diabète sucré dans I'Unité de réanimation de l'Hôpital Universitaire de Parakou (Bénin). Eur Sci J. 2014; 1010:1857-7881. | Article

10. Sobngwi E, Mauvais-Jarvis F, Vexiau P, Mbanya JC and Gautier JF. Diabetes in Africans. Part 2: Ketosis-prone atypical diabetes mellitus. Diabetes Metab. 2002; 28:5-12. | PubMed

11. Pouye $A$ and Leye $A$ NS et al. Acidocétose diabétique dans un service de médecine interne. Dakar Médical. 2003; 48:108-11.

12. Kakoma PK, Kadiebwe DM, Kayembe AM, Kashindi PM, Bugeme M and Mukuku O. Acidocétose diabétique chez l'adulte à l'Hôpital Sendwe de Lubumbashi: à propos de 51 cas. Pan Afr Med J. 2014; 17:1-5. | Article

13. $\mathrm{Mp} \mathrm{M}, \mathrm{Né} \mathrm{D}, \mathrm{Mc} \mathrm{O}, \mathrm{Kt} \mathrm{C}$, Yf $\mathrm{NG}$ and $\mathrm{Cm} A$ et al. Facteurs pronostiques des complications métaboliques du diabète sucré dans un service de réanimation à Abidjan ( $\mathrm{RCl}$ ) Prognosis factors of metabolic complications of diabetes mellitus in a resuscitation department in Abidjan ( RCl ). 2017; 9-13. | Article

14. MBandinga-Mupangu NN. Les facteurs de déconpensation du diabète sucré au Congo (A propos d'une analyse de $\mathbf{2 0 0}$ dossiers de malades). Médeciene d'Afrique Noire. 1991; 38:764-6. | Pdf

15. Wade K.A, Diallo A, Niang E H M, Diatta B and Soumare C T TY. Prise en charge de la cétoacidose diabétique dans le service de réanimation de I'Hôpital Principal de Dakar/Sénégal. RAMUR. 2011; 2:13-7. | Article

\section{Citation:}

Kaké A, Sylla D, Camara MY, Wann TA, Camara I, Camara T, Diaby MM, Samaké M, Andeme NE and Camara A. Ketoacidosis during diabetes mellitus: epidemiological, clinical and management aspects in Malabo - Equatorial Guinea. Intern Med Inside. 2018; 6:2. http://dx.doi.org/10.7243/2052-6954-6-2 